\title{
Dental plaque score index differences in children with mental retardation using two types toothbrush
}

\author{
Ardita Dyna Permata ${ }^{1}$, Susi Sukmasari ${ }^{2}$, Anne Agustina Suwargiani ${ }^{3}$, Arlette Suzy \\ Puspa Pertiwi Setiawan ${ }^{1 *}$ \\ 1Department of Pediatric Dentistry, Faculty of Dentistry Universitas Padjadjaran, Indonesia \\ ${ }^{2}$ Department of Pediatric Dentistry and Dental Public Health, Kulliyyah of Dentistry International \\ Islamic University, Malaysia \\ ${ }^{3}$ Department of Dental Public Health, Faculty of Dentistry Universitas Padjadjaran, Indonesia
}

\begin{abstract}
Introduction: Most of the mentally retarded children may not brush their tooth correctly. They need parents or caregivers to help and supervise the tooth brushing process to reduce the accumulation of dental plaque which may lead to oral diseases. This research was aimed to analyse the most effective toothbrush between parents' toothbrush and regular toothbrush on children with mental retardation. Methods: This research was quasi-experimental with the blind method. Twenty-nine students with mental retardation consisted of boys and girls of YPLB Cipaganti Special Needs School-C (SLB-C) were selected with total sampling. Each individual was divided randomly and being given the parents' toothbrush and regular toothbrush. Parents were responsible for brushing their children's teeth during the period of the study. Plaque scoring was performed on the seventh day. The wash-out period was initiated after the seventh day for one week. Each group was given a different toothbrush from their first toothbrush, and the plaque scoring was performed on the first and seventh day. Plaque scoring was assessed using the Greene Vermillion Index. The data obtained were tested with the Wilcoxon and Mann-Whitney tests. Results: An average difference of plaque index before and after using parents' toothbrush was 0.3 , and the average difference of plaque index before and after using a regular toothbrush was 0.4. There was no significant difference in plaque index changes between these two toothbrushes ( $p$-value $>0.05$ ). Conclusion: Two types of toothbrushes, which are parents' toothbrush and regular toothbrush are able to reduce plaque.
\end{abstract}

Keywords: Parents' toothbrush, regular toothbrush, plaque index, mental retardation.

p-ISSN: 1979-0201; e-ISSN: 2549-6212; Available from: http://jurnal.unpad.ac.id/pjd/article/view/22815

DOI: 10.24198/pjd.vol32no2.22815

Submission: Jul 29, 2019; Accepted: Jul 20, 2020; Published online: Jul 31, 2020

"Corresponding author: Arlette Suzy Puspa Pertiwi Setiawan, Department of Pediatric Dentistry, Faculty of Dentistry Universitas Padjadjaran, Indonesia. Department of Pediatric Dentistry, Faculty of Dentistry Universitas Padjadjaran, Jalan Sekeloa Selatan I, Bandung, West Java, Indonesia, 40132. Phone: +6281395309191; Email: arlette.puspa@fkg.unpad.ac.id 


\section{INTRODUCTION}

It has long been known that the local etiologic factor of dental caries and periodontal disease is plaque. This is due to a collection of bacteria that produce irritants, namely acid, endotoxin, and antigen that gradually dissolved in the tooth and destroy the supporting tissue. ${ }^{1,2}$ Plaque is formed continuously until equilibrium is achieved between plaque cleansing and plaque formation. Plaque can be used to determine the level of oral hygiene of a person, the more accumulation of plaque is formed, the worse the value of a person's oral hygiene..$^{1,3,4}$

The results of the the Indonesia Basic Health Research (Riskesdas) 2018 stated that 93 percent of early childhood, in the age range of 5-6 years, had caries. ${ }^{5}$ This means that only seven percent of children in Indonesia are free from dental caries problem. Children susceptible to caries, especially in children with mental retardation. Children with mental retardation learn more slowly than normal children. ${ }^{6,7}$ Ordinary activities such as tooth brushing can be difficult for them..$^{8-10}$ One of the precautions that can be taken to prevent dental caries and periodontal disease in a mental retardation children is to brush teeth. The choice of toothbrushes and brushing techniques depends on the level of mental and physical retardation. Some companies have designed toothbrushes with various modifications for individuals who have limited abilities. ${ }^{6}$

Previous studies have found that the average plaque index of mentally retarded children before counselling and training was 2.13, and decreased to 1.91 after. ${ }^{11}$ The research done on children with mental retardation who use a modified toothbrush and ordinary toothbrush have lower plaque index results in children who use toothbrush with modification. On the other hand, other studies found no significant differences in the study of 4 types of toothbrush with different modifications. ${ }^{1}$ Modification of oral hygiene aids may be necessary. The manual brush can be modified to suit the hands of patients who can no longer grip and manipulate an object with a small handle. ${ }^{12,13}$ The aim of this study, therefore, was to analyse the most effective toothbrush between parents' toothbrush (modified brush) and regular toothbrush on children with mental retardation.

\section{METHODS}

The type of study chosen based on the objectives to be achieved was quasi experimental. Population taken was student at YPLB Cipaganti Special Needs School-C (SLB-C) Bandung. Sampling technique used was total sampling. The subjects were 29 children with inclusion criteria for girls or boys with mental retardation that their parents or caregivers have been given tooth brushing technique by using parents' toothbrush and regular toothbrush (Figure 1); having teeth 16, 26, 11, 31, 36, and 46; and not using a fixed or fixed orthodontic appliance. Parents' toothbrush is a designed brush with a long handle to help parents brush their child's teeth. Cushioned gum bumper

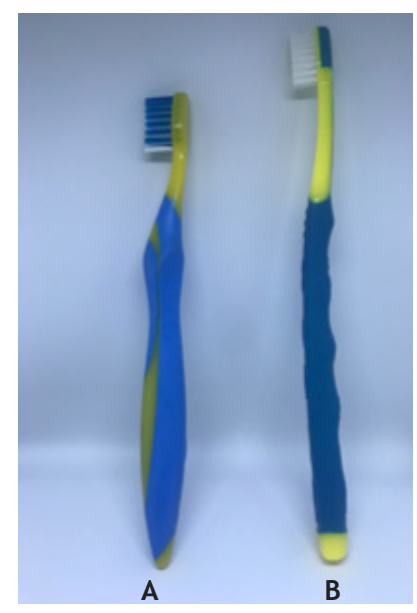

Figure 1. A. Childs' tooth brush; B. Parents' toothbrush

along the edge of the brush head helps to prevent gum irritation. The toothbrush was custom made from the manufacturer and available in the market. Regular toothbrush is a toothbrush that regularly used for children. Both toothbrushes were used by parents to help them brush their child's teeth in this study.

Greene Vermillion index was used to calculate plaque score on teeth $16,26,11,31$, 36 and 46 . The tooth replacer for missing of first molars was second molars, third molars for missing of second molars, 21 and 41 for missing of 11 and 31. The tooth surfaces examined were buccal of 16, 11, 26, and 31, and lingual surfaces 36 and 46. The scores were: 0 (no plaque), 1 (plaque covering less than $1 / 3$ cervical of the tooth), 2 (plaque covering less than $2 / 3$ cervical of the tooth and 3 (plaque covering more than $2 / 3$ cervical of the tooth). Plaque Index was obtained from the total 
value of each tooth examined and divided by the number of teeth examined. ${ }^{14}$

The examination was conducted 4 times. First, examined plaque index value and then was educated about dental health at SLB-C YPLB Cipaganti to the students and accompanying parents. After counseling given, which performed individually by the researcher to each subject along with their parent, each individual group was randomly assigned a toothbrush for home use and a toothbrush report sheet per day. Parents were instructed to fill out the check list on report sheet every time after brushing their children's teeth every day. Second, day-7 and re-examined plaque index value. After the wash-out period for 1 week, parents are not given any instruction. In the second period on day one, the plaque index was reassessed and divided into groups with different toothbrushes with previously used subjects' toothbrushes. On the 7th day a reassessment was made on the subjects.

Based on data obtained from clinical examination, plaque value revealed was presented in the form of numbers. Normality test was initially performed to determine if a data set is well-modelled by a normal distribution and to compute how likely it is for a random variable underlying the data set to be normally distributed. To analyse whether there was a decrease in plaque value before and after treatment and whether there was a difference between brushing with parents brush and child's toothbrushes, a statistical test was performed using paired t-test and unpaired t-test for normal distributed data, whereas for non-distributed data, the Wilcoxon and Mann-Whitney tests were used.

Table 1. Frequency distribution of plaque index before and after treatment

\begin{tabular}{|c|c|c|c|c|c|c|c|c|}
\hline \multirow{3}{*}{ Criteria } & \multicolumn{4}{|c|}{ Parents tooth brush } & \multicolumn{4}{|c|}{ Regular tooth brush } \\
\hline & \multicolumn{2}{|c|}{ Before } & \multicolumn{2}{|c|}{ After } & \multicolumn{2}{|c|}{ Before } & \multicolumn{2}{|c|}{ After } \\
\hline & $\mathbf{F}$ & $\%$ & $\mathbf{F}$ & $\%$ & $\mathbf{F}$ & $\%$ & $\mathbf{F}$ & $\%$ \\
\hline Good & 0 & 0 & 3 & 10 & 1 & 4 & 6 & 20 \\
\hline Moderate & 24 & 83 & 22 & 76 & 16 & 55 & 21 & 73 \\
\hline Poor & 5 & 17 & 4 & 14 & 12 & 41 & 2 & 7 \\
\hline Total & 29 & 100 & 29 & 100 & 29 & 100 & 29 & 100 \\
\hline
\end{tabular}

RESULTS

Study on 29 children mental retardation aged 9-16 years consisting of 10 girls and 19 boys. Frequency distribution of plaque index before and after brushing with parents' toothbrush and regular toothbrush is presented in Table 1, the table shows that initial plaque index of the child was moderate and poor.

Table 1 shows a plaque index of mentally retarded children before treatment using parents' toothbrush majority was moderate, 24 individuals $(83 \%)$ and the rest were bad in as many as 5 individuals $(17 \%)$ from the total subjects $(29$ children). Plaque index after treatment using ordinary toothbrush by parents was as much as 22 individuals (76\%), poor in as many as 4 individuals $(14 \%)$, and the rest was good in as much as 3 individuals (10\%). Table 1 also shows a plaque index of mentally retarded children before treatment using a common toothbrush majority at moderate level, which were in 16 individuals $(55 \%)$, second frequency was bad category in as many as 12 individuals (41\%), and either 1 person (4\%) from the total subjects (29 children). Plaque index after treatment using regular toothbrush by the parents was in 21 individuals (73\%), either in as many as 6 people (20\%), and the rest was bad in

Table 2. Average plaque index before and after brushing with parents' toothbrush and regular toothbrush

\begin{tabular}{|c|c|c|c|c|c|c|}
\hline \multirow{2}{*}{$\begin{array}{l}\text { Tooth } \\
\text { brush }\end{array}$} & \multirow{2}{*}{$\mathrm{n}$} & \multicolumn{2}{|c|}{ Average plaque index } & \multirow{2}{*}{$\begin{array}{l}\text { Mean difference median } \\
\text { (Min-Max) }\end{array}$} & \multicolumn{2}{|c|}{$\begin{array}{l}\text { p-value of Normality test (Saphiro } \\
\text { Wilk) }\end{array}$} \\
\hline & & $\begin{array}{c}\text { Before } \\
\text { Median (Min-Max) }\end{array}$ & $\begin{array}{c}\text { After } \\
\text { Median (Min-Max) }\end{array}$ & & Before & After \\
\hline Parents & 29 & $1.3(1-2.3)$ & $1(0.5-1.3)$ & $0.3(-0.5-1.2)$ & 0.001 & 0.004 \\
\hline Regular & 29 & $1.3(0.7-2.8)$ & $1(0.3-2.3)$ & $0.4(-0.2-1.9)$ & 0.14 & 0.1 \\
\hline
\end{tabular}




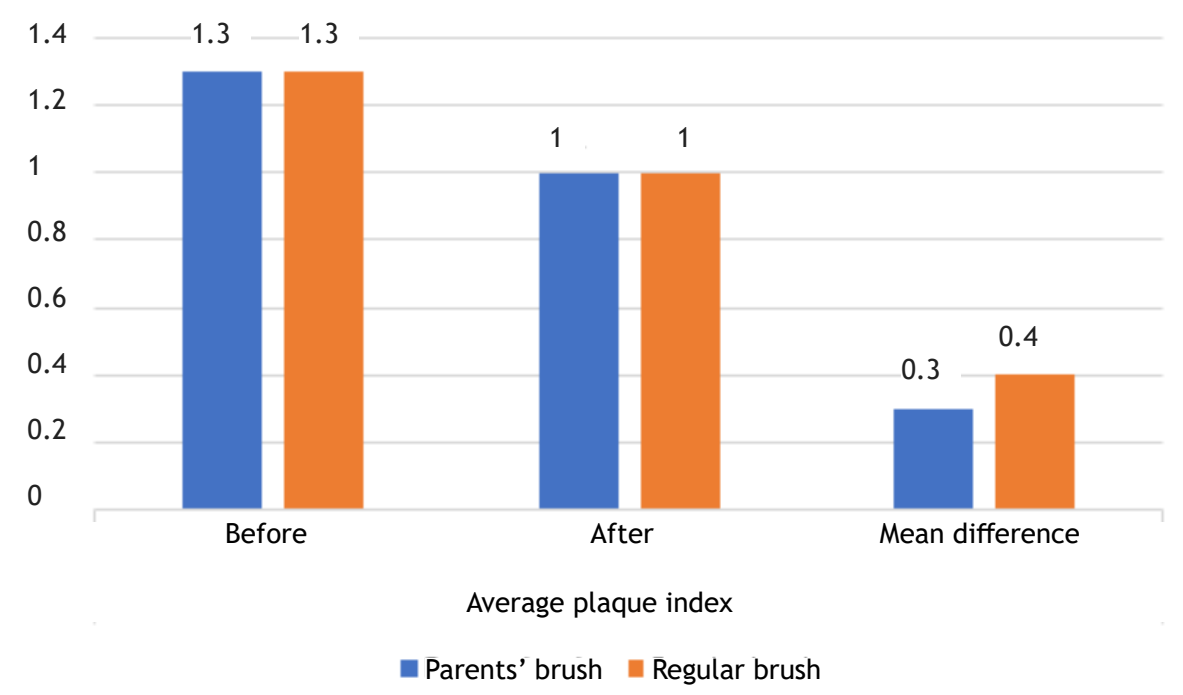

Figure 2. Average plaque index before and after brushing with parents' toothbrush and regular toothbrush

as much as 2 individuals (7\%). The average plaque index before and after brushing with both types of toothbrushes is presented in Table 2 and Figure 2, the results showed a decrease in plaque after tooth brushing with both toothbrush types. It also shows the mean differences in different plaque indices for both toothbrushes. The average difference of parents' toothbrush plaque index was 0.3 and the highest mean difference of plaque index was after brushing with regular toothbrush, which was 0.4.

Before analysing the plaque index hypothesis before and after using parent's toothbrush and regular toothbrush, a data normality test was conducted using the Shapiro-Wilk test. The results of normality and homogeneity tests can be seen in Table 2. The normality test results showed the value of $p$ ( $a$ arithmetic) in each group were lower than 0.05 . This result shows that the value of the difference in plaque index was not normally distributed. Therefore, the statistical testing cannot be conducted by paired sample t-test, instead using Wilcoxon and Mann-Whitney tests. These tests can be used to investigate whether two independent samples were selected from populations having the same distribution. The Mann-Whitney $U$ test is often used when the assumptions of the independent samples t-test are violated. A similar nonparametric test used on dependent sample is the Wilcoxon signed-rank test. ${ }^{15}$

Table 3. Analysis of differences in the effects of toothbrush on plaque reduction

\begin{tabular}{|c|c|c|c|c|}
\hline \multirow{3}{*}{ Tooth brush } & \multirow[t]{3}{*}{$\mathrm{n}$} & \multicolumn{2}{|c|}{ Plaque index mean } & \multirow[t]{3}{*}{$\mathrm{p}$-value } \\
\hline & & Before & After & \\
\hline & & Median (Min - Max) & Median (Min - Max) & \\
\hline \multicolumn{5}{|l|}{ Wilcoxon analysis } \\
\hline Parents & 29 & $1.3(1-2.3)$ & $1(0.5-1.3)$ & 0.001 \\
\hline Regular & 29 & $1.3(0.7-2.8)$ & $1(0.3-2.3)$ & $<0.001$ \\
\hline \multicolumn{5}{|l|}{ Mann-Whitney analysis } \\
\hline Parents & 29 & \multicolumn{2}{|c|}{$0.3(-0.5-1.2)$} & 0.169 \\
\hline Regular & 29 & \multicolumn{2}{|c|}{$0.4(-0.2-1.9)$} & \\
\hline
\end{tabular}

Table 3 shows the results of the average pairs of plaque index data occurred over different time periods for both types of toothbrushes. The Wilcoxon statistical test results show the p-value which was lower than 0.05 , which indicated that there was a significant difference between the use of two toothbrushes.
The table also shows differences in the plaque indices before and after using parents' and ordinary toothbrushes. The result of statistical test by Mann Whitney shows that the $p$-value was also higher than 0.05 , which suggested that there was no significant difference between the use of two toothbrushes. 


\section{DISCUSSION}

Table 1 show that most plaque index frequencies of 29 mental retardation children before treatment were at moderate and poor levels. This is because mental retardation children have more caries and a higher prevalence of gingivitis and periodontal disease than the general population. Children with mental retardation have more caries and a higher prevalence of gingivitis and periodontal disease as compared to the general population. ${ }^{16}$

Nutrition and dietary patterns such as increased consumption of foods and beverages with high sugar content, unbalanced intake of nutritious foods, fruits, and vegetables is a major effect on oral health. Most mental retardation children consume sugar more frequent as compare to other normal children, leading to increasing plaque formation and higher caries risk..$^{8,10}$

Oral manifestations in children with mental retardation such as malocclusion and excessive amounts of teeth can be a factor that complicates tooth cleaning by toothbrushes. ${ }^{17} \mathrm{~A}$ lack of knowledge about oral health can affect the treatment of plaque control. This is compounded with the limitations of mentally retarded children in thinking and having no good control over their arm and hand movements making it difficult for them to perform daily activities such as brushing. After treatment, there was a change in the number of plaque-level frequency levels in a child's mental retardation.

The results of this study indicate that there is a difference effect of toothbrush used by parents to changes in the index of dental plaque of mental retardation children as shown in Table 2. These also explain that changes occurring before and after treatment were significant plaque index decreases $(p<0.05)$ with plaque index average before and after using parents' toothbrush 0.3 or decrease of $23 \%$ and mean different plaque index before and after using ordinary toothbrush 0.4 or decrease as much as $30 \%$. These results can occur because toothbrushes are an effective way to control plaque. Plaque begins to appear after one to two days and a regular and correct toothbrush will certainly help the process of plaque reduction. ${ }^{18}$ Parents' toothbrush and regular toothbrush have a small brush head that is suitable for the size of the child's mouth cavity and allows parents to clean all child's teeth. Parents' toothbrush and regular toothbrushes also have a soft bristle brush as suggested by Carranza and can help clean teeth effectively. ${ }^{1}$ Tooth brushing done by parents in this study may be the cause of plaque change because some mental retardation children cannot brush their teeth properly, so a mentally retarded child who is not self-sufficient requires the help of a parent or caregiver with better motor skills to brush. This suggests that parents or caregivers have an important role to maintain the oral health of the mental retardation child. ${ }^{19}$

Both toothbrushes show the largest plaque index change by regular toothbrushes. The results of observations between parents' toothbrush and regular toothbrush is that the later have a stronger feather than parents' toothbrush. This may lead to the removal of plaque more effectively by using a regular toothbrush. This happen also because the regular toothbrush without modification in the handle is a toothbrush design commonly used by parents. The results of observation, parents and children involved in this study first use parents' toothbrush. Parents' toothbrushes have a handle that is longer than the regular toothbrush, so parents must adapt to parents' toothbrush. Behavioral changes can occur if they have experienced the awareness process, interested in the stimulus, judging whether and not the stimulus, trying to behave, and adaptation. ${ }^{19}$

Table 2 shows differences in plaque index change with parents' toothbrush treatment and regular toothbrushes were not statistically significant $(p>0.05)$. This study is in line with the results of research according to Newman et $\mathrm{al}^{1}$ that in the study of 3 types of toothbrush modification, there is no significant difference between the three types of toothbrush modification. The ability of children or parents to carry out oral health maintenance is constrained by parents' time, the ability of children to work together, the environment and physical conditions that provide health care, and the level of involvement of parents plays a major role in the change in the mental retardation of children's plaque index. ${ }^{20}$ These things affect the effectiveness of toothbrushes used and can make the difference in plaque index change between the two toothbrushes insignificant. The correct application of toothbrushes is more important 
than the toothbrush used itself, such as tooth brushing techniques, duration of toothbrushing, frequency of brushing, and individual skills in toothbrushing. ${ }^{21}$

Every parent who were included in this study is instructed to fill the tooth brushing report every day and give rewards for children who brushed their teeth regularly 4 days in a row, but based on reports received, not all children successfully brushed teeth by parents for 7 days consecutive.

Brushing child's teeth is something new for some parents. The responsibility of parents to do other things can be an obstacle to continue to brush the teeth to the child. From the observation, most parents do not know how to brush their teeth with the correct technique. The correct technique has been given to parents during the day of counseling, but it could be because the habits that have been brushing techniques from each parent may vary and influence the plaque index.

Some mentally retarded children have low adaptation rates. This shown in 10 of 29 children who followed the study were not routinely brushed because it was difficult to open the mouth and lazy tooth brushing based on parents' reports given. One week duration spent in this study on both parents toothbrush and regular toothbrush is too short to change a behaviour ${ }^{22}$, which was the limitation of this study.

\section{CONCLUSION}

Both parents' toothbrush and regular toothbrush used by parents are able to significantly reduce plaque and also alter plaque indices in children with mental retardation. Regular toothbrush changes the plaque index more than parents' toothbrush.

\section{REFERENCES}

1. Newman M, Takei H, Klokkevold P, Carranza F. Carranza's Clinical Periodontology. $13^{\text {th }}$ ed. Philadelphia: Saunders-Elsevier; 2018. p. 944.

2. Lang NP, Lindhe J. Clinical Periodontology and Implant Dentistry. $6^{\text {th }}$ ed. Hoboken: WileyBlackwell; 2015. p. 1480.

3. Murakami S, Mealey BL, Mariotti A, Chapple ILC. Dental plaque-induced gingival conditions. J Clin Periodontol. 2018; 89(Suppl 1): S17-27.
DOI: $10.1002 /$ JPER.17-0095

4. Bashirian S, Shirahmadi S, SeyedzadehSabounchi S, Soltanian AR, Karimi-Shahanjarini A, Vahdatinia F. Association of caries experience and dental plaque with sociodemographic characteristics in elementary school-aged children: A cross-sectional study. BMC Oral Health. 2018; 18(1): 7. DOI: 10.1186/s12903017-0464-4

5. National Institute of Health Research and Development (NIHRD). Indonesia Basic Health Research (RISKESDAS) 2017-2018. Jakarta: Ministry of Health of the Republic of Indonesia; 2018.

6. Lamba R, Rajvanshi H, Sheikh Z, Khurana M, Saha R. Oral hygiene needs of special children and the effects of supervised tooth brushing. Int J Sci Stud. 2015; 3(5): 30-5. DOI: 10.17354/ ijss/2015/342

7. Relwani AH, Kiran S, Bhatt R, Patel M. Impact of dental health education on "specific learning needs" children. Int J Clin Pediatr Dent. 2016; 9(1): 31-4. DOI: 10.5005/jpjournals-10005-1329

8. Stefanovska E, Nakova M, RadojkovaNikolovska V, Ristoska S. Tooth-brushing intervention programme among children with mental handicap. Bratisl Lek Listy. 2010; 111(5): 299-302.

9. Dewi WN, Gunarhadi G, Wagimin W. Selfdevelopment learning in increasing activity of daily living in children with mild mental disability. 2017; 2(3): 43-54.

10. Farrag J. Daily living activities of children with mild mental retardation: Effect of nursing intervention. Port Said Sci J Nurs. 2016; 3(1): 86-98. DOI: $10.21608 /$ pssjn.2019.32296

11. Rizkika N, Baehaqi M, Putranto RR. Efektifitas menyikat gigi dengan metode Bass dan horizontal terhadap perubahan indeks plak pada anak tunagrahita. Odonto Dent J. 2014; 1(1): 29-33. DOI: $10.30659 /$ odj.1.1.29-33

12. McGrath $C$, Zhou N, Wong HM. A systematic review and meta-analysis of dental plaque control among children and adolescents with intellectual disabilities. J Appl Res Intellect Disabil. 2019; 32(3): 522-32. DOI: 10.1111/ jar. 12561

13. Zhou N, Wong HM, Wen YF, Mcgrath C. Oral health status of children and adolescents 
with intellectual disabilities: A systematic review and meta-analysis. Dev Med Child Neurol. 2017; 59(10): 1019-26. DOI: $10.1111 /$ dmcn.13486

14. Kolawole KA, Oziegbe EO, Bamise CT. Oral hygiene measures and the periodontal status of school children. Int J Dent Hyg. 2011; 9(2): 143-8. DOI: 10.1111/j.16015037.2010.00466.x

15. Kerby DS. The simple difference formula: an approach to teaching nonparametric correlation. Compr Psychol. 2014; 3(1): 1-9. DOI: 10.2466/11.IT.3.1

16. Solanki J, Khetan J, Gupta S, Tomar D, Singh M. Oral rehabilitation and management of mentally retarded. J Clin Diagn Res. 2015; 9(1): ZE01-06. DOI: 10.7860/ JCDR/2015/11077.5415

17. Feldberg I, Merrick J. Intellectual disability and dental services: Experience from Israel. Front Public Health. 2014; 2: 133. DOI: 10.3389/fpubh.2014.00133

18. Naik R, Mujib BRA, Telagi N, Anil BS, Spoorthi
BR. Contaminated tooth brushes-potential threat to oral and general health. J Family Med Prim Care. 2015; 4(3): 444-8. DOI: 10.4103/2249-4863.161350

19. Lin YL, Yen YY, Chen HS, Liu YC, Chang CS, Chen $C M$, et al. Child dental fear in low-income and non-low-income families: A school-based survey study. J Dent Sci. 2014; 9(2): 165-71. DOI: $10.1016 / j$.jds.2013.02.022

20. Çolak H, Dulgergil CT, Dalli M, Hamidi MM. Early childhood caries update: A review of causes, diagnoses, and treatments. J Nat Sci Biol Med. 2013; 4(1): 29-38. DOI: 10.4103/0976$\underline{9668.107257}$

21. Hayasaki H, Saitoh I, Nakakura-Ohshima K, Hanasaki M, Nogami Y, Nakajima T, et al. Tooth brushing for oral prophylaxis. Jpn Dent Sci Rev. 2014; 50(3): 69-77. DOI: 10.1016/j. jdsr.2014.04.001

22. Purnama T, Rasipin R, Ngatemi N. Tedi's behavior change model to improving brushing teeth behavior parents. J Appl Health Manag Tech. 2020; 2(1): 1-12. 